\title{
Apuntes
}

\section{La convivencia en aislamiento}

\author{
Mario Sanz Cruz
}

Técnico de Señales Marítimas del faro de Mesa Roldán

Las condiciones de la vida en aislamiento han hecho que la convivencia entre torreros no siempre haya sido un camino de rosas. En el libro Faro de Mesa Roldán. Apuntes para una historia (2003), que recoge multitud de anécdotas sacadas de las comunicaciones con la Jefatura y los libros de Diario de Servicio, encontramos distintos ejemplos.

En este faro, son varios los torreros que se pelearon y amenazaron. Entre 1863 y 1882, Eustasio Page, que era todo un carácter, tuvo problemas con Francisco Manresa por causas personales, con Ángel Gallego para colocar a su yerno, con Nicolás Arbucias por incompatibilidad de caracteres y con Serafín Pérez León que desapareció sin despedirse. Como ejemplo basta este oficio de Page a la Jefatura quejándose de Manresa, sólo 16 días después de haberse inaugurado el faro:

El poco celo que el Torrero Auxiliar de dicho faro presta al servicio, lo sumamente holgazán y la grande indocilidad me hacen fuerza a poner en su conocimiento como en la mañana del día de ayer al salir por la puerta principal del establecimiento, enfrente a los tres pasos de distancia, encontré recién echadas una porción de cáscaras de patatas, saliendo a este tiempo dicho Torrero Auxiliar le dije con la mayor prudencia hiciera el favor de quitar aquello de allí, pues no era sitio de echar basura y dijo que había sido la niña, empezando a echar ojos y hablarme de una manera tan imperiosa que no era sino un insulto.

El día que recibió la carta del pagador donde le decía se le acreditaba a razón de $6 \mathrm{R}$. diarios desde la escuela hasta su presentación en esa, en vez de dejar el farol y la caja de servicio como es debido, lo tiraba de la mano diciendo que por menos de tres cuartos no subiría a encender al día siguiente, hizo lo mismo con el obturador, y no se le puede decir nada por que contesta de un modo que insulta, de tal suerte que se hace inaguantable.

De aquí resulta que ya ha roto un cristal de una ventana de su sala y otro cristal del farol de mano o linterna de servicio apareció roto y niega que haya sido él, por esta circunstancia y las referidas le empleo todo lo menos que puedo en el trabajo porque repito, hace las cosas de muy mala gana y lo peor de todo, el no poder decirle hazlo de este modo por lo mal que contesta, falta muy grave para el servicio de un faro y que no siempre podré tolerar. Faro de Mesa de Roldán 17 de Enero de 1864.

En 1889, el desmemoriado Miguel Sampol se peleó con Alfredo Foglietti, del que le separaba un abismo generacional:

Habiéndome manifestado el Torrero $3^{\circ} \mathrm{D}$. Alfredo Foglietti a la salida de este faro, que fue el día 5 a la madrugada, que solo era para una o dos noches y habiendo transcurrido tres días con tres noches y ya van a los cuatro días, (pues son la 1,30 de la tarde)

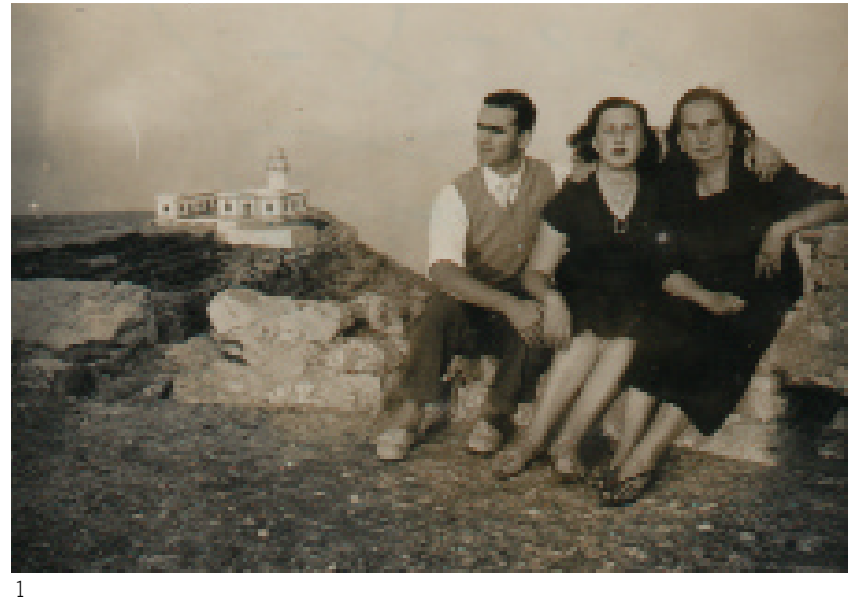

y no haberse presentado, lo pongo en conocimiento de $\mathrm{V}$. para si lo tiene a bien dé instrucciones para cuando se presente, además debo poner en su conocimiento que sin haberme pedido autorización se meten gentes extrañas en su casa y creo que no solamente es falta de respeto, sé que también es faltar al Reglamento, y de este modo me veo en el caso de no poderle mandar nada, pues hasta su Señora dice en un tono bastante altanero que su marido no está acostumbrado a que le manden y figúrese $V$. en que pareja de novicios me han metido, por consiguiente espero de su bondad se sirva juzgar la manera con que sirvo este faro (Miguel Sampol - Faro de Mesa Roldán).

A consecuencia de la comunicación que se ha servido dirigir a este faro de fecha 17 del que rige, el Torrero $3^{\circ}$, ha promovido un escándalo de improperios, amenazas, desafios e insultos, que no he podido prescindir de llamar a los Carabineros en auxilio y defensa del servicio y personal, para evitar sus consecuencias, tal fue el escándalo que promovió y no solamente en este faro, sino que a la hora de encender se fue a los Caseríos de abajo (o vulgarmente, de la Mesa) y promovió otro escándalo o motín, abandonando de esta manera el servicio y, asi es que parece que a todo trance quiere chocar y comprometer, cuando me valgo de toda la prudencia que me caracteriza.

Lo que pongo en el conocimiento de $\mathrm{V}$. para que si no es molestarle se sirva disponer lo mejor en beneficio del servicio, esperando se sirva dispensar las molestias (Miguel Sampol - Faro de Mesa Roldán).

Pero Foglietti también tiene algo que decir:

En virtud de la repulsa que $V$. a tenido a bien comunicarme por quejas producidas injustificadas por el Torrero encargado de este faro; tengo el honor de poner en conocimiento de V. como dichas quejas no tienen motivo fundado, advirtiéndole que el que no 

Foto: Colección José Pérez Suárez

2. Los fareros y sus familias comiendo juntos en 1956. Foto: Colección José Pérez Suárez

3. Los técnicos de Mesa Roldán con el ingeniero, el cura y otros compañeros en 1960. Foto: Colección José Pérez Suárez

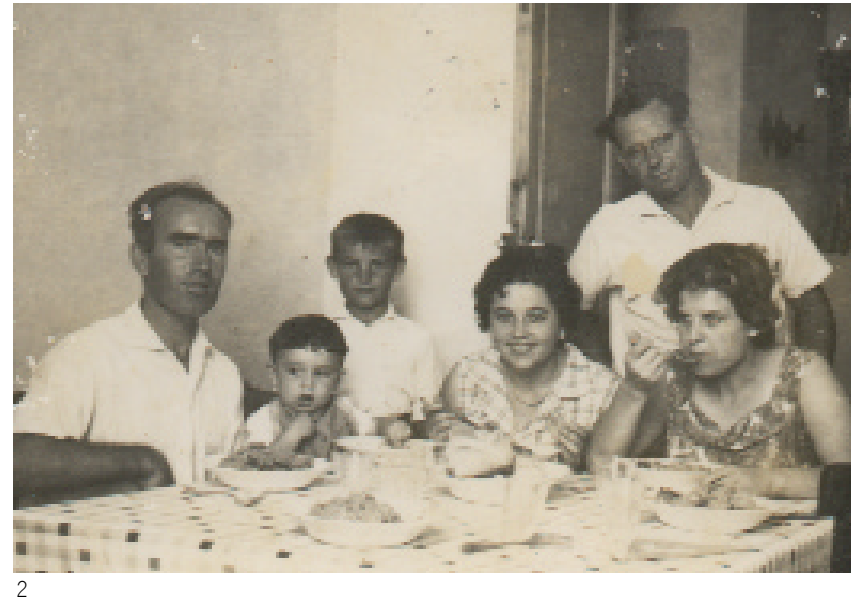

cumple con su deber es el Torrero encargado Sr. Sampol, pues hasta ahora me he valido de mi buena paciencia y no he querido molestar a Vds. en lo más mínimo, por consiguiente hoy me veo en el caso de comunicar a V. lo que sigue: El Torrero $1^{\circ} \mathrm{Sr}$. Sampol hace tiempo viene abusando de mi buena prudencia; como de costumbre y muy a menudo suele ir a Carboneras, resultando su llegada al Establecimiento a muy deshoras de la noche y de tal modo se presenta, que me es vergonzoso nombrar la frase, porque deshonra al Cuerpo, al mismo tiempo de alterar mis servicios y faltándome sobremanera, por mi buena cachaza he tolerado sus impertinencias.

Por lo tanto ruego a $\mathrm{V}$. encarecidamente se digne dar conocimiento al Sr. Ingeniero de lo que ocurre, deseando a la mayor brevedad posible seamos trasladados uno de los dos a cualquier faro de esta provincia, de lo contrario no respondo de las averías y disgustos que en este punto puedan originarse, pues me es de todo punto imposible tener que seguir mis buenos servicios en compañía de tan mal hombre, que a cada momento interrumpe mi buena conducta y me hace sacar de mis casillas, al mismo tiempo cuento con testigos que pueden justificar quien de los dos cumple con su deber. Faro de Mesa Roldán 22 de Julio de 1889. El Torrero $3^{\circ}$ Alfredo Foglietti.

En 1905 José Molina y Fernando Ferrón Ilevaron sus peleas al juzgado:

Día 2 Turno $2^{\circ}$. Diez minutos antes de la hora de apagar y en la cámara de iluminación, empezó a provocarme el Torrero $1^{\circ}$, bajándome sin apagar ni hacer las limpiezas, lo que acreditaré cuando sea necesario. Sin novedad en el turno. Cubierto. Ferrón. 2 Noviembre 1905.

Día 3 Turno $1^{\circ}$. Sin novedad en el turno. Despejado. Ferrón. Todo cuanto queda escrito por el Torrero $2^{\circ}$ es una solemne

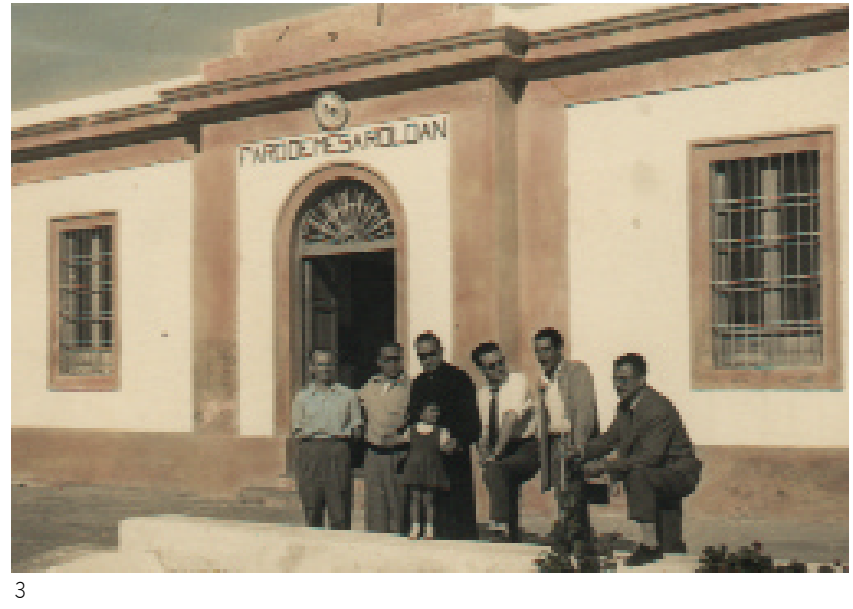

mentira, pues la verdad es que su objeto era de marcharse del faro antes de la hora que tiene por costumbre y dando, y provocando la cuestión para marcharse como así lo hizo, manifestando que tenía la autorización para marcharse del Sr. Ingeniero Jefe y a pesar de estar de servicio de semana, así lo hizo, y con sus provocaciones, me dijo que en cuanto volviera de un viaje que tiene en proyecto para ir a Almería me daría un tiro y me rompería la cabeza. José Molina. 3 Noviembre 1905.

Pero el caso más grave es el del torrero encargado Simón Fuentes, que escribe este relato el día 3 de mayo de 1931:

Media hora poco más o menos antes de encender y cuando me encontraba preparándole la comida a una caballería menor que tengo de mi propiedad, se me presentó el Torrero agregado Antonio Fernández Pérez y sin mediar palabra alguna, me disparó tres tiros con una pistola, que afortunadamente no hizo blanco, viéndome precisado a correr y abandonar el Faro para poder salvar la vida.

Por suerte la sangre no llegó al río y, además de estas anécdotas, en este faro se han forjado grandes amistades y extensos periodos de paz y sosiego, como puede verse en las fotografías adjuntas. 